\title{
Does placement of rubber dam effect the arterial oxygen saturation in children? A clinical study
}

\author{
Mesut Enes Odabaş*, Ceren Deveci and Ayşegül Ölmez \\ Department of Pediatric Dentistry, Faculty of Dentistry, University of Gazi \\ 8. Cadde 82.Sokak 06510, Emek Ankara, TURKEY
}

\begin{abstract}
The aim of this study was to evaluate the effect rubber dam placement on the arterial oxygen saturation level in children. Thirty children were randomly allocated to one of two groups: Group $\mathrm{A}-15$ patients in this group had rubber dam isolation of the maxilla, and Group B - 15 patients had rubber dam isolation of the mandible. The children were healthy and cooperative. The arterial oxygen saturation was taken before each injection, before starting the intervention, i.e. $5 \mathrm{~min}$ after the injection, and at 5 -min intervals. All $\mathrm{SpO}_{2}$ values were recorded every 30 seconds over a 30 minute period. There were no statistically significant differences in arterial oxygen saturation in all reading sessions for both groups $(P>0.05)$. The use of rubber dam did not decrease the arterial oxygen saturation level in children.
\end{abstract}

\section{Key words}

Arterial oxygen saturation, Children,

Rubber dam

\section{Introduction}

Rubber dam has been available to the dental profession for over 140 years ${ }^{1)}$. The use of rubber dam during dental treatment confers three main advantages: control of cross-infection, protection and improving treatment efficiency ${ }^{2}$. Rubber dams' use has been recommended by the British Society of Pediatric Dentistry and the American Academy of Pediatric Dentistry ${ }^{3,4)}$. However, its placement has the potential to alter air flow in both the oral and nasal cavities.

Hypoxia is a pathological condition in which the body as a whole or a region of the body is deprived of adequate oxygen supply. Hypoxia commonly arises in dental patients during and after dental surgery ${ }^{5}$. This dangerous condition requires the clinician to monitor patient's vital signs specifically pulse rate and blood oxygen content for any signal of trouble. Tissues vary considerably in their sensitivity to hypoxia. Neural cells tolerate hypoxia for only a few minutes whereas bladder

\footnotetext{
* Correspondence to: Mesut Enes Odabaş

E-mail: mesut@gazi.edu.tr

Received on September 14, 2010; Accepted on June 30, 2011
}

smooth muscle may survive for several days without oxygen $^{6}$. This has important implications in the management of oxygen transport and monitoring of tissue hypoxia in medically-compromised patients. Therefore, hypoxia should be a concern in dental procedures, especially in medically-compromised patients and children.

Goodday and Crocker $^{7)}$ evaluated the effect of rubber dam placement on arterial blood oxygen saturation in dental patients. They found no significant change in arterial blood oxygen saturation $\left(\mathrm{SpO}_{2}\right)$ before and after rubber dam isolation. There are few studies evaluating the effect of rubber placement dam on arterial oxygen saturation in children and its effect on children has not been studied extensively ${ }^{8,9)}$.

The purpose of this study was to evaluate the effect rubber dam placement on the arterial oxygen saturation level in children.

\section{Materials and Methods}

Participants, including 17 boys and 13 girls ranging between 4 and 12 years of age (mean age 7.6 years) were selected from the patient population at the 


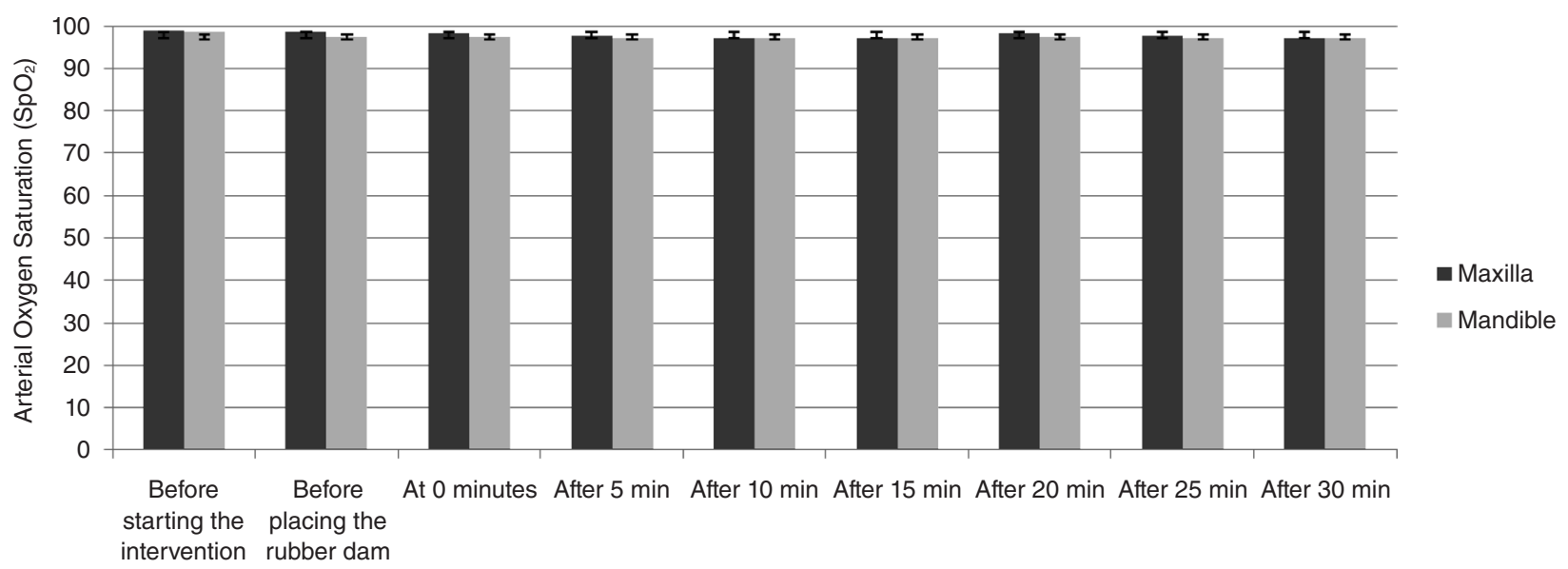

Fig. 1 Measurements of percentage oxygen saturation $\left(\mathrm{SpO}_{2}\right)$ at different times in patients who had rubber dam isolation of the mandible $(\mathrm{n}=15)$ and maxilla $(\mathrm{n}=15)$. Data are mean \pm SEM.

University of Gazi, Department of Pediatric Dentistry. The children were healthy and cooperative. The procedure, possible discomfort, or risks as well as possible benefits were explained fully to parents of the children involved. The informed consent was obtained from the patients and parents. Thirty children were randomly allocated to one of two groups: Group $\mathrm{A}-15$ patients in this group had rubber dam isolation of the maxilla, and Group B - 15 patients had rubber dam isolation of the mandible.

A standard maxillary infiltration injection was administered for maxilla, and an inferior alveolar block anesthesia was administered for mandible using articaine 4\% with 1:200000 epinephrine (Maxicaine $^{\circledR}$, Vem İlaç San. Ve Tic. Ltd., Ankara, Türkiye). The arterial oxygen saturation was taken before each injection, before starting the intervention, i.e. 5 min after the injection, and at 5-min intervals using pulse oximetry (Datex-Ohmeda TuffSAT, GE Healthcare, Chalfont St. Giles, UK). All $\mathrm{SpO}_{2}$ values were recorded every 30 seconds over a period of 30 minutes. Operative procedures were done on each patients during taking the data of $\mathrm{SpO}_{2}$. The results were statistically analyzed using ANOVA and Scheffe's test at a significance level of 0.05.

\section{Results}

Figure 1 shows the arterial oxygen saturation level of the two groups. There were no statistically significant differences in arterial oxygen saturation in all reading sessions for both groups $(P>0.05)$.

\section{Discussion}

Use of pulse oximetry to detect chronic or intermittent hypoxemia is a valid, reliable, and frequently used method ${ }^{10)}$. When oxygen saturation is obtained by pulse oximetry, it is abbreviated as $\mathrm{SpO}_{2}$, with the reference rate range of $97 \%$ to $99 \%$ in a healthy individual breathing room air. An oxygen saturation value of $90 \%$ is the lowest value that is acceptable and is generally equated with blood oxygen $\left(\mathrm{PaO}_{2}\right)$ of $60 \mathrm{mmHg}^{11)}$. Saturation of $90 \%$ and below should be considered a marker for hospitalization for condition such as pneumonia or acute heart failure ${ }^{12,13)}$.

In this study, there were no statistically significant differences in arterial oxygen saturation for both groups $(P>0.05)$ and none of the groups showed oxygen saturation below value of $90 \%$. However, there are few human clinical studies evaluating the effect of rubber dam placement on the arterial oxygen saturation for the purpose of outcome comparison in children. Bello and Darwish ${ }^{9)}$ investigated the effect of restorative dental treatment on blood pressure, pulse rate and arterial oxygen saturation in children. They found some insignificant desaturations below the preoperative baseline and they reported that the maximum decrease occurred during rubber dam application.

Our results also in agreement with Goodday and Crocker's ${ }^{7)}$ study. They found that the rubber dam, whether properly or improperly placed, showed no statistically significant effect on the oxygen saturation. In addition, Poiset et al. ${ }^{8)}$ examined the effect of routine dental procedures on heart rate and 
oxygen saturation. They completed all procedures under rubber dam and found no statistically significant change in the oxygen saturation during dental procedures.

There are several medical conditions related to hypoxia such as asthma, congestive heart failure, pneumonia and chronic pulmonary diseases. One of the most important medical conditions that related with hypoxia is asthma. Acute asthma is the most common diagnosis in children admitted to hospital in Western society and is characterised by acute episodes of obstruction related to loss of control of airway inflammation mostly in response to a viral respiratory tract infection ${ }^{14}$. Sole et al. $^{15)}$ found that an $\mathrm{SpO}_{2}<94 \%$ was associated with increased sensitivity of the asthma attack. It has been suggested that if a rubber dam can induce similar changes, then the patient's health could be at risk ${ }^{7)}$.

On the other hand, Mungo et al. ${ }^{16)}$ found that cotton rolls could trigger a hyperreactive airway response in a sensitive subject. Rubber dam should be used judiciously to avoid possible respiratory compromise or aggravation ${ }^{17}$. Moreover, a case has been reported where enamel dust generated as a result of preparing natural teeth triggered a bronchoconstrictive response ${ }^{18}$.

In conclusion, there was no significant change in arterial oxygen saturation in children before and after rubber dam isolation was performed. The benefits of rubber dam are numerous and should be use in dental procedure as a standard of care.

\section{References}

1) Elderton, R.J.: A modern approach to the use of rubber dam - 1. Dent Pract Dent Rec 21: 187-193, 1971.

2) Ahmad, I.A.: Rubber dam usage for endodontic treatment: a review. Int Endod J 42: 963-972, 2009.

3) American Academy on Pediatric Dentistry Clinical Affairs Committee-Pulp Therapy subcommittee; American Academy on Pediatric Dentistry Council on Clinical Affairs: Guideline on pulp therapy for primary and young permanent teeth. Pediatr Dent 30: 170-174, 2008.
4) Fayle, S.A., Welbury, R.R. and Roberts, J.F.: British Society of Paediatric Dentistry: a policy document on management of caries in the primary dentition. Int J Paediatr Dent 11: 153-157, 2001.

5) Gandy, S.R.: The use of pulse oximetry in dentistry. J Am Dent Assoc 126: 1274-1276, 1278, 1995.

6) Leach, R.M. and Treacher, D.F.: Oxygen transport-2. Tissue hypoxia. BMJ 317: 1370-1373, 1998.

7) Goodday, R.H. and Crocker, D.A.: The effect of rubber dam placement on the arterial oxygen saturation in dental patients. Oper Dent 31: 176-179, 2006.

8) Poiset, M., Johnson, R. and Nakamura, R.: Pulse rate and oxygen saturation in children during routine dental procedures. ASDC J Dent Child 57: 279-283, 1990.

9) Bello, L.L. and Darwish, S.K.: Effect of restorative dental procedures on vital signs in children. Saudi Dental Journal 6: 78-82, 1994.

10) Salyer, J.W.: Neonatal and pediatric pulse oximetry. Respir Care 48: 386-396; discussion 397-388, 2003.

11) Schutz, S.L.: Oxygen saturation monitoring by pulse oximetry. In: AACN Procedure Manual for Critical Care. 5th ed. (Wiegand, D.J. and Carlson, K.K. eds.) Elsevier Saunders, St. Louis, MO, 2005, pp.101107.

12) Carratala, J., Fernandez-Sabe, N., Ortega, L., Castellsague, X., Roson, B., Dorca, J. et al.: Outpatient care compared with hospitalization for community-acquired pneumonia: a randomized trial in low-risk patients. Ann Intern Med 142: 165-172, 2005.

13) Fine, M.J., Auble, T.E., Yealy, D.M., Hanusa, B.H., Weissfeld, L.A., Singer, D.E. et al.: A prediction rule to identify low-risk patients with community-acquired pneumonia. N Engl J Med 336: 243-250, 1997.

14) Belessis, Y., Dixon, S., Thomsen, A., Duffy, B., Rawlinson, W., Henry, R. et al.: Risk factors for an intensive care unit admission in children with asthma. Pediatr Pulmonol 37: 201-209, 2004.

15) Sole, D., Komatsu, M.K., Carvalho, K.V. and Naspitz, C.K.: Pulse oximetry in the evaluation of the severity of acute asthma and/or wheezing in children. $J$ Asthma 36: 327-333, 1999.

16) Mungo, R.P., Kopel, H.M. and Church, J.A.: Pediatric dentistry and the child with asthma. Spec Care Dentist 6: 270-273, 1986.

17) Steinbacher, D.M. and Glick, M.: The dental patient with asthma. An update and oral health considerations. J Am Dent Assoc 132: 1229-1239, 2001.

18) Housholder, G.T. and Chan, J.T.: Tooth enamel dust as an asthma stimulus. A case report. Oral Surg Oral Med Oral Pathol 75: 599-601, 1993. 